\title{
Analysis of conditional contingency using ACTUS2 with examples from studies of animal behavior
}

Received: 23 October 2000 / Received in revised form: 28 May 2001 / Accepted: 19 June 2001 / Published online: 26 September 2001 (C) Springer-Verlag and ISPA 2001

\begin{abstract}
In this paper we present ACTUS2, the second version of ACTUS (Analysis of Contingency Tables Using Simulation). ACTUS2 has many new features, including analysis of data in which dependencies that make some combinations of properties impossible are hypothesized. Because ACTUS2 explicitly simulates such hypotheses, it can be used without loss of accuracy to analyze small amounts of data in large tables with many zeros or very low frequencies. We illustrate these features with two studies of animal behavior: interactions of male individuals with other individuals in groups of captive, mature Triturus marmoratus pygmaeus (newts); and agonistic interactions between pairs of male juvenile Diplodus sargus (the sparid fish, white sea-bream). Both significantly frequent, and significantly infrequent, co-occurrences that had biologically meaningful interpretations were revealed.
\end{abstract}

Keywords Contingency tables · Transition analyses · Diplodus sargus . Triturus marmoratus pygmaeus . Simulation statistics

\section{Introduction}

ACTUS was originally designed to test an hypothesis of the independence of two classifications of the same small collection of cases (Estabrook and Estabrook 1989), by simulating that hypothesis with a microcomputer thousands of times to estimate the realized significances of the observed numbers of cases simultaneously

Communicated by R.F. Oliveira

G.F. Estabrook (

Department of Ecology and Evolutionary Biology,

University of Michigan, Ann Arbor, MI 48109-1048, USA

e-mail: estabrook@umich.edu

V.C. Almada · F.J. Almada · J.I. Robalo

Unidade de Investigação em Eco-Etologia, Instituto

Superior de Psicologia Aplicada, Rua Jardim do Tabaco 44,

1100 Lisbon, Portugal classified in each pair of classes, chosen one from each classification. The motivation at that time was to be able to analyze statistically, but simply and accurately, sparse data from historical archives. Such data are often qualitative and evidenced by a limited number of cases.

Since that time, ACTUS has been used in a number of other applications, including studies of animal behavior (e.g., Almada and Santos 1995; Gonçalves and Almada 1997, 1998; Oliveira and Almada 1998). As a consequence of that experience, it became apparent that in many cases it was natural to test specific hypotheses of partial dependence of one classification on the other. This dependence arises from the impossibility in some situations for some pairs of classes to simultaneously contain any cases at all.

For example, suppose we observe an individual and note each time his or her behavior changes, within the context of a small number of behavioral stereotypes. Each of these observed changes can be construed as a case. These observed cases can be classified in two ways: according to the behavior just ceased and according to the behavior just begun. Because we observe changes, it is not possible for an observed behavioral change to belong to the same behavioral stereotype class in both the "before" and the "after" classification. An appropriate hypothesis to simulate in order to estimate significances of frequent or rare observed sequential pairs of behaviors should postulate such impossible combinations.

Null hypotheses

Hypotheses postulating the independence of two classifications are limited in number, but there is a large number of ways that conditions of dependency of one classification on another could be postulated. The dependencies we discuss here arise when membership in a given class of one classification precludes membership in one or more classes of the other. In these situations, the two classifications are no longer independent because the 
probabilities with which a case belongs to the classes of one classification are hypothesized to vary depending on the class of another classification to which that case is known to belong; in particular, the probability of membership in some classes becomes 0 as a consequence of belonging to other classes.

In order to simulate an hypothesis of dependence, all the varied, conditional probabilities must be explicitly specified, not just the zeros. Each possible way to specify them gives rise to a different hypothesis of dependence. The choice of any one in particular needs to be justified in the context of the scientific questions whose answers are sought through the comparison of observed data with the predictions of the null hypothesis chosen. There is usually some arbitrariness associated with such choices, which can be tempered by appeal to intellectual aesthetics. These, of course, vary from one scholar to another. Here we present one plausible approach.

Arbitrarily designate the two classifications with the letters $\mathrm{R}$ and $\mathrm{C}$. We represent the observed cases as counts in a matrix in which the classes of $\mathrm{R}$ are represented by the rows and the classes of $\mathrm{C}$ are represented by the columns. In the boxes of this matrix appear the counts of the number of observed cases that simultaneously belong to the classes corresponding to the row and column in which the box occurs.

To postulate one possible null hypothesis embodying the concept of independence first postulate that the probability with which a case belongs to a class of $\mathrm{R}$ is proportional to the frequency with which observed cases belong to that class, and similarly, postulate the probabilities with which cases belong to classes of C. Next assign a case to a class of $\mathrm{R}$ using these row probabilities, and assign the same case to a class of $\mathrm{C}$ using these column probabilities, which do not change as a consequence of the class of $\mathrm{R}$ already chosen. The concept of independence is realized because these probabilities do not change, i.e., are not dependent on which class of the row classification has already been chosen. An identical hypothesis would be achieved if the column class were chosen first. Under this hypothesis, the expected number of cases in a given box is given by the product of the probabilities that a case belongs to the classes of the row and column of that box times the number of cases observed. The sum of these expected numbers in any given row equals the number of cases observed in the class of that row, and similarly for columns.

Here we discuss situations in which the scientific context enables us to recognize a "causal" order for the two classifications under study. Suppose that, depending on which class of $\mathrm{C}$ is observed for a case, some of the classes in the row classification may become impossible for that case. With what probabilities should that case occur in one of the remaining possible classes? We must answer this question in order to complete the definition of this null hypothesis of dependence. Our approach to postulating these conditional probabilities for the classes of $\mathrm{R}$ given a class of $\mathrm{C}$ is as follows. For classes of $\mathrm{C}$ for which all classes of $\mathrm{R}$ remain possible, assign probability to a class of $\mathrm{R}$ proportional to the frequency of cases observed in that class of $\mathrm{R}$, as in the hypothesis of independence above. For each of the other classes of $\mathrm{C}$, some classes of $\mathrm{R}$ remain possible and others become impossible. For such a class of $\mathrm{C}$, postulate the conditional probability of a possible class of $\mathrm{R}$ to be proportional to the frequency with which cases, observed in any of the possible classes of R (and in any class of $\mathrm{C}$ ), occur in it. We justify this approach by supposing that the impossible classes of $\mathrm{R}$ never existed and that the cases observed in them were never observed. Now in this supposed column there are no impossible rows, so we define probabilities as if all classes of $\mathrm{R}$ were possible.

Because row probabilities are column-dependent, they are possibly different for each column. To calculate the expected number of cases observed in each box of the matrix, multiply the probability of the class of the column times the conditional probability of the class of the row times the number of cases observed. The sum of the expected values of the boxes within a column is equal to the number of cases observed in the class of that column. However, because of the dependencies on columns, the sum of the expected numbers of cases within rows does not always equal the number of cases observed in the class of that row.

Similar arguments and definitions would apply if the classification of the rows had been designated as "causal" and the probabilities of the possible classes of $\mathrm{C}$ defined to be conditional. This would usually produce a different hypothesis, which would generate different estimated significances. The direction of dependence is an important part of the hypothesis to be tested, and deserves to be justified in the context of the scientific question under study.

\section{The ACTUS2 algorithm}

The realized significances, under the C-dependent or Rdependent hypothesis, of the observed frequencies (and other statistics of interest) are estimated by the simulation of thousands of tables, similar to the observed table in that the names of the row classes and column classes are the same, and there are as many cases counted in each table as were observed. However the cases in the simulated tables are "observed" by simulation, not by scientific observation, to ensure that they are samples of the null hypothesis whose predictions we seek to compare with the observed data.

For the C-dependent hypothesis, to "observe" a simulated case, first ACTUS2 uses a random number generator to choose, with probabilities proportional to observed frequencies, a column class. Next, ACTUS2 again uses a random number generator to choose, with probabilities depending on which column class was chosen, a row class. Finally, ACTUS2 increments the count of cases in the box corresponding to the row and column chosen. When as many cases have been "observed" by simulation as were observed scientifically, the matrix of counts 
of simulated cases is compared to the matrix of counts of observed cases.

These comparisons are made in two basic ways: calculated statistics intended to measure deviation from counts expected under the null hypothesis; and direct comparison of observed counts. A classic statistic to measure deviation from expected values is $\chi^{2}$. It is calculated as the sum over all the boxes of (the squared difference between the observed and the expected counts in a box divided by the expected count in that box). Under the hypothesis of independence described above, if enough cases have been observed so that the expected count in each box is at least 5 , then the probability that $\chi^{2}$ assumes a given range of values can be approximated by a known distribution, called the chi-square distribution, which can be used to look up the realized significance of the value of $\chi^{2}$ calculated from observed counts. If the null hypothesis does not hypothesize independence, such as the C-dependent or R-dependent hypotheses in question here, or if the expected count in some boxes is substantially less than 5 , then use of the chi-square distribution may result in errors. ACTUS2 does not use the chi-square distribution but instead simulates an accurate estimate of the realized significance of the value of $\chi^{2}$ calculated from the observed counts as follows. A value of $\chi^{2}$ is calculated from each simulated table. The fraction of simulated tables for which the value of $\chi^{2}$ is greater or equal to the value of $\chi^{2}$ calculated from the observed counts is this estimated significance. If thousands of tables are simulated, this method of estimating the significance of $\chi^{2}$ is quite accurate even if the null hypothesis postulates dependencies or the expected values are low.

Another simpler calculated statistic to measure observed deviation from expected counts is $\mathrm{SAD}$, the sum over the boxes of the absolute difference between the observed count and the expected count. Chi-square differs from SAD in that it weights more heavily larger deviations, e.g., a table with most frequencies near expected but a few very far from expected would have a higher $\chi^{2}$ value than a table with the same SAD value but all frequencies equally different from expected. SAD was not used in the past before calculating power was available because its probability distribution was unpredictable. ACTUS2 calculates a value and simulates a significance for SAD, using the same approach as for $\chi^{2}$.

ACTUS2 reports the significance of observed counts in two tables: one for large counts and one for small counts. Each table has the same number of rows and columns as the table of observed counts. Each box in the table for large counts reports the significance of the observed count as the fraction of simulated tables with counts in that box greater than or equal to the count in that box of the observed table. If for a box very few of the simulated tables have counts equal to or greater than the observed count, then the observed count in that box is atypically large. Similarly, each box in the table for small counts reports the significance of the observed count as the fraction of simulated tables with counts in that box less than or equal to the count in that box of the observed table. If for a box very few of the simulated tables have counts less than or equal to the observed count, then the observed count in that box is atypically small. When thousands of tables are simulated, these realized significances accurately reflect the predictions of the null hypothesis.

Those interested can find and download ACTUS2, with user documentation and examples at http://wwwPersonal.umich.edu/ gfred/.

\section{Some statistical considerations}

Do simulation procedures such as ACTUS2 actually get the same answers as do procedures based on parametric distributions and mathematical assumptions and manipulations? The answer to this question is "yes", when such mathematical procedures exist. This was the remarkable result published by Efron (1979), which shocked the statistical world and launched the rapid growth of simulation methods. In cases where explicit mathematical procedures exist, simulation still has two major advantages: simulation is easier for people to calculate (because the repeated calculation are done by a computer); and simulation is much easier for natural and social scientists to understand (because it usually involves less sophisticated mathematics). Both of these advantages apply to ACTUS2, but there are other advantages as well.

In data analytic cases where the mathematical procedures needed to get the exact answer do not exist, often mathematical procedures, sometimes requiring additional assumptions, do exist that can make good approximations. Do not mathematically explicit procedures already exist to solve the problems ACTUS2 can solve? Yes again, almost. Feinberg (1987), Christiansen (1997) and Manly (1997) have all treated contingency tables under hypotheses of dependency similar to those ACTUS2 can simulate. These authors describe a variety of sophisticated mathematical methods that, together with additional assumptions, can make accurate approximations, when observed cases are numerous. When observed cases are few, and especially when they are made fewer by large tables, the accuracy of these approximations deteriorates. However, our difficulty in calculating them, or in understanding them, does not. In such cases, simulation methods, such as ACTUS2, can be easy to use, easy to understand, accurate, and fast.

Once the simulation of hypotheses was shown to be a valid alternative in cases where exact mathematical methods were known, it became clear that simulation could be applied to approximate distributions in cases where exact mathematical methods were unknown. Marriott (1979) was among the first to discuss how many simulations were needed to ensure the accuracy of these approximations. Manly (1997) gives a more general treatment of this question and states that a 5\% confidence level can be recognized with near certainty by 1,000 simulations; $1 \%$ with 5,000. Indeed, Efron and 
Tibshirani (1986) have shown how simulation can be used to determine the statistical accuracy of estimations made by mathematical methods.

As a caveat lest we become overly concerned with statistical precision, Thomas (2000) reminds us in his discussion of two-way contingency tables that we combine statistical analysis with intuition, knowledge, and context to infer real-life conclusions.

The purpose of the statistical analysis is to disclose how observed data differ from what particular hypotheses might predict. This reveals aspects of the observed data that require explanations beyond those already stated in the hypothesis simulated (or treated mathematically), so that such explanations might be proposed. With this goal in mind, we illustrate ACTUS2 with some applications to behavioral problems.

\section{Application to behavioral problems}

In this paper we apply ACTUS2 to two examples of analysis of transitions between consecutive behavioral acts of the same individual. The analysis of transitions between consecutive acts of the same individual or consecutive acts of two interacting individuals has been the subject of much ethological research and has always raised a number of difficulties. For discussions of the problems raised by this type of analysis see Slater (1973), Fagen and Mankovich (1980), Bakeman and Gottman (1986), and Gama (1989).

The classical approach to this problem has been the construction of transition matrices that were analyzed as contingency tables. Statistics like $\chi^{2}$ were used to test for the presence of first-order Markovian processes, i.e., a simple dependence of the frequency of each class of behavior pattern on the nature of the preceding act (for examples of alternative approaches see Chatfield and Lemon 1970; Hazlett and Estabrook 1974; Oden 1977; Steinberg 1977). The analysis of contingency tables had to be modified to allow for the fact that the cells in the diagonal of the matrix were structural zeros, since transitions between the same class of act performed by the same individual where often very difficult to identify accurately (Slater and Ollason 1972; Slater 1973). This approach, once very popular in ethological studies, was subjected to many restrictions, many of them derived from the properties and assumptions of the statistical distribution used in the test. Some of these restrictions have already been mentioned in the previous section, namely the problems raised by the use of the chi-square distribution when the table contained very low expected values of less than five. The amounts of data considered necessary to perform such analysis were considerably high and some authors recommended values higher than $5 R^{2}$ up to $10 R^{2}$, although even sometimes as much as $50 R^{2}$ were used, $R$ being the number of behavior categories used in the matrix (see Steinberg 1977).

In this respect, the procedure presented in this paper has many important advantages when used in the analy- sis of sequence data. The number of behavioral transitions can be much lower than in other approaches and the presence of zeros in the matrix and very low expected frequencies are no longer a problem. In addition it solves a problem often overlooked by other approaches, that of impossible transitions. Indeed in many studies impossible transitions are not limited to the diagonal. A bird, for instance, cannot pass directly from sitting on the eggs to killing a prey $3 \mathrm{~km}$ away. Many other absurd transitions are often found in transition matrices. A final advantage of this approach is the simultaneous accurate assessment of the significance of the whole table and that of the individual cells, avoiding the use of a posteriori tests.

To illustrate this approach we use two sets of data: in one set we apply this procedure to classical behavioral material, sequences of behavior of male newts during social interactions. It is a small sample based on sequences of behavior of four male marbled newts (Triturus marmoratus pygmaeus) kept in bisexual groups for several weeks. The social behavior of male newts has been thoroughly studied (e.g., Halliday 1974; Arntzen and Sparreboom 1989; Green 1989; Zuiderwijk 1986, 1990; Sparreboom and Teunis 1990; Faria 1993, 1995). This example was selected to show to what extent ACTUS2, using a very small sample, succeeds in capturing the salient features of the behavior of the newts already known from other approaches in previous studies. The other set of data consists of a much larger number of transitions between acts recorded during agonistic encounters of juveniles of the white sea-bream, the sparid fish Diplodus sargus. In contrast with the previous set, the agonistic behavior of these inshore marine fish had not been analyzed before, and ACTUS2 was used as a tool to explore the social interactions of the juveniles of this species.

\section{Methods}

Both newts and white sea-bream were kept for several weeks in captivity in groups of at least six individuals. Data from six male newts observed for equal amounts of time were included in this study, while the data for sea-bream came from 24 individuals observed for equal amounts of time. The details of maintenance, captivity and descriptions of behavior will be published elsewhere (Robalo and Almada, in press; V.C. Almada et al., unpublished work). The observed newts were breeding males, kept in groups that also contained mature females, while the white sea-bream were all juveniles, less than $10 \mathrm{~cm}$ total length.

All data were collected during focal observations (sensu Martin and Bateson 1993) and were recorded using time bases of $1 \mathrm{~min}$ for newts and $30 \mathrm{~s}$ for sea-bream. Only behavior patterns involved in agonistic and/or sexual interactions were considered in this study.

As in its present form ACTUS2 does not support tables with more than ten rows and ten columns, the much higher number of behavior categories in the original record had to be aggregated to form the lists presented below.

The categories of newt behavior were basically derived from the descriptions presented by Halliday (1974; for T. vulgaris), Zuiderwijk (1986, 1990; for T. marmoratus and T. cristatus) and Sparreboom and Teunis (1990; for T. marmoratus), with minor additions and modifications. 
The categories of male newt behavior are described bellow:

1. Move-to-the-front: a rapid approach towards another newt with short hops when the four legs are stretched, usually stops when the newt is in front of the other, presenting the flank.

2. Whip: a strong and rapid tail lash in the direction of another newt, typically a female.

3. Fan/Wave: a combination of several variations of tail movements.

4. Alert: a static posture in which the newt typically has the head raised, the forelegs stretched. Sometimes all four legs are stretched.

5. Sniff: a newt sniffs another newt.

6. Lean-in: a newt, standing on the forelegs, bends the rear part of the body over another, sometimes touching the other newt with tail and/or flanks.

7. Cat-buckle: the newt arches so that the body adopts a kink in the middle.

8. Static: the animal stays still.

9. Move-Away: a newt moves away from another

10. Approach/Land-On: the animal approaches another newt or while swimming lands on another newt's body.

The categories of white sea-bream behavior are described in the following list. The details of these behavioral patterns will be presented elsewhere (V.C. Almada et al., unpublished work).

1. Approach: slow swimming towards another fish.

2. Withdrawal: slow swimming away from another fish.

3. Threatening: one fish turns to another one with dorsal, anal and pelvic fins erected and a somewhat stiff body. The mouth of the threatening fish may be open.

4. Chasing: rapid swimming with frequent changes of direction in pursuit of another fleeing fish.

5. Fleeing: rapid swimming of the attacked fish from its attacker with all fins folded.

6. Charging: rapid swimming directly to another fish, with dorsal, anal and pelvic fins erected. The mouth is sometimes open.

7. Bite/butt: an overt attack in which the fish butts and often bites the opponent.

8. Submission: the submissive fish lies on one side presenting its dorsal fin to the opponent reaching an angle up to $90^{\circ}$ with the normal position. All fins are usually folded and the fish swims slowly towards the substratum.

9. Tail beating: rapid undulatory movement of the body with or without contact with one opponent usually closer than one body length.

10. Fight: may occur in two forms, circle-fight and mouth-fight. Circle-fight occurs when two fishes, in an anti-parallel position, swim rapidly around a central axis with successive charges towards the caudal fin of the opponent. Dorsal, anal, and pelvic fins are erected. Mouth-fight occurs when two fishes approach facing each other with all fins erected. Body is folded in a $\mathrm{C}$ position and both fishes simultaneously charge each other repeatedly. Mouth is open and there is contact with the snout of the opponent.

\section{Results}

The newt raw data are presented in Table 1 and their analysis is presented in Table 2. Tables 3, 4 present the raw data and the analysis for white sea-bream. In Tables 2, 4 we present in each box the significance of high counts above the significance of low counts.

The transition matrices of both data sets yielded highly significant values both for $\chi^{2}$ and SAD. Indeed, for newts, the $\chi^{2}$ of the observed table was $193.5(n=268$, $d f=81$ ), it was equaled or exceeded 9 times out of 10,000 simulations $(P<0.001)$. The value of SAD was 149.6 and it was equaled or exceeded 0 times out of 10,000 simulations $(P<0.001)$. For white sea-bream the $\chi^{2}$ of the observed table was $552.8 \quad(n=828, d f=81)$, and it was equaled or exceeded 0 times out of 10,000 simulations $(P<0.001)$. The value of SAD was 438.1 and it was equaled or exceeded 0 times out of 10,000 simulations $(P<0.001)$. This means that the analysis reveals not only the transitions that are especially frequent but conversely identifies those that are unlikely to occur. Since the cells with significant values are numerous in both tables we limited our analysis to cells significant at the arbitrary limit, $P<0.1$.

In the case of newts, inspection of Table 2 shows that counts greater than expected $(P<0.01)$ are: Fan/WaveWhip, Lean-In-Whip, Cat-Buckle-Whip, Whip-Fan/Wave, Approach/Land-on-Sniff, Fan/Wave-Static, Move-AwayStatic, Alert- Approach/Land-on. The same table shows that values lower than expected $(P<0.01)$ are: StaticWhip, Approach/Land-on-Fan/Wave, Move-Away-Alert, Fan/Wave-Sniff, Static-Sniff, Sniff-Approach/Land-on.

In the case of white sea-bream inspection of Table 4 shows that counts greater than expected $(P<0.01)$ are: Approach-Threatening-Charging-Chasing-Charging-Byte/ Butt, Submission-Tail beating-Withdrawal-Fleeing, Submission-Withdrawal, Fight- Withdrawal. The same table shows for values lower than expected $(P<0.1)$ that: Approach was unlikely to be followed by: Withdrawal, Charging, Chasing, Byte/Butt and Tail beating; With-

Table 1 Transition matrix of newt raw data

\begin{tabular}{|c|c|c|c|c|c|c|c|c|c|c|}
\hline & $\begin{array}{l}\text { Move-to- } \\
\text { the-front }\end{array}$ & Whip & Fan/Wave & Alert & Sniff & Lean-in & Cat-buckle & Static & Move-away & $\begin{array}{l}\text { Approach/ } \\
\text { Land-over }\end{array}$ \\
\hline Move-to-the-front & - & 0 & 0 & 3 & 2 & 0 & 0 & 3 & 0 & 1 \\
\hline Whip & 1 & - & 5 & 0 & 1 & 0 & 1 & 3 & 2 & 1 \\
\hline Fan/Wave & 0 & 4 & - & 3 & 0 & 0 & 0 & 12 & 0 & 1 \\
\hline Alert & 0 & 0 & 1 & - & 4 & 0 & 1 & 8 & 2 & 11 \\
\hline Sniff & 0 & 0 & 0 & 3 & - & 1 & 0 & 12 & 6 & 1 \\
\hline Lean-in & 0 & 2 & 0 & 0 & 0 & - & 0 & 1 & 0 & 0 \\
\hline Cat-buckle & 0 & 2 & 0 & 0 & 0 & 0 & - & 0 & 0 & 0 \\
\hline Static & 2 & 3 & 13 & 22 & 6 & 1 & 0 & - & 11 & 28 \\
\hline Move-away & 0 & 1 & 0 & 0 & 0 & 0 & 0 & 18 & - & 3 \\
\hline Approach/Land-over & 2 & 2 & 0 & 6 & 17 & 1 & 0 & 29 & 5 & - \\
\hline
\end{tabular}


Table 2 Analysis of newt data. In each box the significance (units per 1000 data sets) high counts is presented above the significance of low counts. Significant high counts and significant low counts are indicated by numbers $<100$

\begin{tabular}{|c|c|c|c|c|c|c|c|c|c|c|}
\hline & $\begin{array}{l}\text { Move-to- } \\
\text { the-front }\end{array}$ & Whip & Fan/Wave & Alert & Sniff & Lean-in & Cat-buckle & Static & $\begin{array}{l}\text { Move- } \\
\text { away }\end{array}$ & $\begin{array}{l}\text { Approach/ } \\
\text { Land-over }\end{array}$ \\
\hline Move-to-the-front & $\begin{array}{l}1,000 \\
1,000\end{array}$ & $\begin{array}{r}1,000 \\
618\end{array}$ & $\begin{array}{r}1,000 \\
516\end{array}$ & $\begin{array}{l}133 \\
959\end{array}$ & $\begin{array}{l}292 \\
912\end{array}$ & $\begin{array}{r}1,000 \\
900\end{array}$ & $\begin{array}{r}1,000 \\
932\end{array}$ & $\begin{array}{l}577 \\
651\end{array}$ & $\begin{array}{r}1,000 \\
408\end{array}$ & $\begin{array}{l}788 \\
535\end{array}$ \\
\hline Whip & $\begin{array}{l}240 \\
969\end{array}$ & $\begin{array}{l}1,000 \\
1,000\end{array}$ & $\begin{array}{r}4 \\
999\end{array}$ & $\begin{array}{r}1,000 \\
127\end{array}$ & $\begin{array}{l}809 \\
501\end{array}$ & $\begin{array}{r}1,000 \\
838\end{array}$ & $\begin{array}{l}100 \\
994\end{array}$ & $\begin{array}{l}854 \\
302\end{array}$ & $\begin{array}{l}417 \\
829\end{array}$ & $\begin{array}{l}923 \\
272\end{array}$ \\
\hline Fan/Wave & $\begin{array}{r}1,000 \\
670\end{array}$ & $\begin{array}{r}26 \\
995\end{array}$ & $\begin{array}{l}1,000 \\
1,000\end{array}$ & $\begin{array}{l}590 \\
639\end{array}$ & $\begin{array}{r}1,000 \\
92\end{array}$ & $\begin{array}{r}1,000 \\
780\end{array}$ & $\begin{array}{r}1,000 \\
850\end{array}$ & $\begin{array}{r}52 \\
972\end{array}$ & $\begin{array}{r}1,000 \\
124\end{array}$ & $\begin{array}{l}974 \\
114\end{array}$ \\
\hline Sniff & $\begin{array}{r}1,000 \\
615\end{array}$ & $\begin{array}{r}1,000 \\
253\end{array}$ & $\begin{array}{r}1,000 \\
166\end{array}$ & $\begin{array}{l}692 \\
519\end{array}$ & $\begin{array}{l}1,000 \\
1,000\end{array}$ & $\begin{array}{l}245 \\
967\end{array}$ & $\begin{array}{r}1,000 \\
821\end{array}$ & $\begin{array}{l}131 \\
923\end{array}$ & $\begin{array}{r}38 \\
987\end{array}$ & $\begin{array}{r}988 \\
61\end{array}$ \\
\hline Lean-in & $\begin{array}{r}1,000 \\
949\end{array}$ & $\begin{array}{r}12 \\
999\end{array}$ & $\begin{array}{r}1,000 \\
809\end{array}$ & $\begin{array}{r}1,000 \\
654\end{array}$ & $\begin{array}{r}1,000 \\
712\end{array}$ & $\begin{array}{l}1,000 \\
1,000\end{array}$ & $\begin{array}{r}1,000 \\
978\end{array}$ & $\begin{array}{l}624 \\
744\end{array}$ & $\begin{array}{r}1,000 \\
745\end{array}$ & $\begin{array}{r}1,000 \\
604\end{array}$ \\
\hline Cat-buckle & $\begin{array}{r}1,000 \\
963\end{array}$ & $\begin{array}{r}5 \\
1,000\end{array}$ & $\begin{array}{r}1,000 \\
870\end{array}$ & $\begin{array}{r}1,000 \\
758\end{array}$ & $\begin{array}{r}1,000 \\
799\end{array}$ & $\begin{array}{r}1,000 \\
979\end{array}$ & $\begin{array}{l}1,000 \\
1,000\end{array}$ & $\begin{array}{r}1,000 \\
527\end{array}$ & $\begin{array}{r}1,000 \\
826\end{array}$ & $\begin{array}{r}1,000 \\
703\end{array}$ \\
\hline Move-away & $\begin{array}{r}1,000 \\
634\end{array}$ & $\begin{array}{l}724 \\
639\end{array}$ & $\begin{array}{r}1,000 \\
178\end{array}$ & $\begin{array}{r}1,000 \\
30\end{array}$ & $\begin{array}{r}1,000 \\
68\end{array}$ & $\begin{array}{r}1,000 \\
764\end{array}$ & $\begin{array}{r}1,000 \\
838\end{array}$ & $\begin{array}{r}1 \\
999\end{array}$ & $\begin{array}{l}1,000 \\
1,000\end{array}$ & $\begin{array}{l}790 \\
397\end{array}$ \\
\hline Approach/Land-over & $\begin{array}{l}412 \\
832\end{array}$ & $\begin{array}{l}900 \\
249\end{array}$ & $\begin{array}{r}1,000 \\
5\end{array}$ & $\begin{array}{l}950 \\
100\end{array}$ & $\begin{array}{r}6 \\
998\end{array}$ & $\begin{array}{l}567 \\
796\end{array}$ & $\begin{array}{r}1,000 \\
574\end{array}$ & $\begin{array}{l}158 \\
883\end{array}$ & $\begin{array}{l}843 \\
272\end{array}$ & $\begin{array}{l}1,000 \\
1,000\end{array}$ \\
\hline
\end{tabular}

Table 3 Transition matrix of white sea-bream raw data

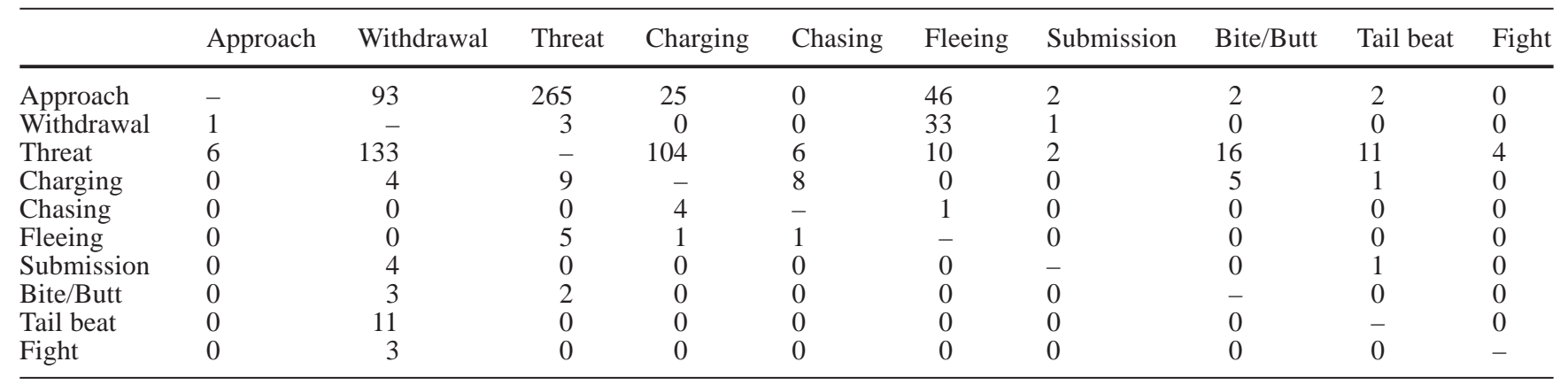

drawal-Threatening and Charging; Threatening-Fleeing; Charging-Threatening and Fleeing; Fleeing-Withdrawal; Tail beating- Threatening

\section{Discussion}

In the case of the newt data set, the results presented in the previous section are not particularly surprising by themselves. What is remarkable in our view is the fact that with such a small number of transitions (268) so many significant relationships could be detected even that confirmed the results of previous works. However, some interesting points are worth mentioning. In general, sexual behavior patterns like Fan/Wave, Cat-buckle and Lean-in all preceded Whip with high probability, which in turn preceded Fan/Wave. Previous authors have considered Whip as a behavior expressing a very high sexual motivation and likely to occur in later phases of courtship sequences
(Zuiderwijk 1990). Because courtship in newts occurs typically as a succession of bouts, it is interesting to see that Whip is very likely to precede Wave/Fan, a behavior common at the beginning of bouts that is sometimes supposed to spread in the water pheromones that would attract females from a distance (e.g., Griffiths 1996). Thus our analysis apparently captured a pattern of transitions between successive courtship bouts. Other interesting transitions were Approach to Sniff and Alert to Approach. Indeed, Sniff another newt is often the first action observed after an Approach, while before moving to Approach another animal the newts often assume an Alert posture.

As an example of a meaningful use of the counts that are significantly lower than expected, we would refer to Static-Whip, which indicates that a transition from immobility to a behavior with a high level of motivation is unlikely and requires intermediate patterns.

In the case of white sea-bream, two behavior groups should be considered: group 1 contains Approach, 
Table 4 Analysis of white sea-bream data. In each cell the significance of high counts is presented above the significance of low counts. Significant high counts and significant low counts are indicated by numbers $<100$

\begin{tabular}{|c|c|c|c|c|c|c|c|c|c|c|}
\hline & Approach & Withdrawal & Threat & Charging & Chasing & Fleeing & Submission & Bite/Butt & Tail beat & Fight \\
\hline Approach & $\begin{array}{l}1,000 \\
1,000\end{array}$ & $\begin{array}{r}1,000 \\
0\end{array}$ & $\begin{array}{r}0 \\
1,000\end{array}$ & $\begin{array}{r}1,000 \\
0\end{array}$ & $\begin{array}{r}1,000 \\
0\end{array}$ & $\begin{array}{l}635 \\
425\end{array}$ & $\begin{array}{l}742 \\
509\end{array}$ & $\begin{array}{r}1,000 \\
0\end{array}$ & $\begin{array}{r}997 \\
15\end{array}$ & $\begin{array}{r}1,000 \\
121\end{array}$ \\
\hline Withdrawal & $\begin{array}{l}379 \\
920\end{array}$ & $\begin{array}{l}1,000 \\
1,000\end{array}$ & $\begin{array}{r}1,000 \\
0\end{array}$ & $\begin{array}{r}1,000 \\
0\end{array}$ & $\begin{array}{r}1,000 \\
361\end{array}$ & $\begin{array}{r}0 \\
1,000\end{array}$ & $\begin{array}{l}280 \\
961\end{array}$ & $\begin{array}{r}1,000 \\
218\end{array}$ & $\begin{array}{r}1,000 \\
369\end{array}$ & $\begin{array}{r}1,000 \\
772\end{array}$ \\
\hline Threat & $\begin{array}{l}181 \\
911\end{array}$ & $\begin{array}{l}529 \\
513\end{array}$ & $\begin{array}{l}1,000 \\
1,000\end{array}$ & $\begin{array}{r}0 \\
1,000\end{array}$ & $\begin{array}{l}808 \\
318\end{array}$ & $\begin{array}{r}1,000 \\
0\end{array}$ & $\begin{array}{l}740 \\
509\end{array}$ & $\begin{array}{l}165 \\
892\end{array}$ & $\begin{array}{l}177 \\
897\end{array}$ & 939 \\
\hline Charging & $\begin{array}{r}1,000 \\
763\end{array}$ & $\begin{array}{r}986 \\
37\end{array}$ & $\begin{array}{l}748 \\
362\end{array}$ & $\begin{array}{l}1,000 \\
1,000\end{array}$ & $\begin{array}{r}0 \\
1,000\end{array}$ & $\begin{array}{r}1,000 \\
31\end{array}$ & $\begin{array}{r}1,000 \\
822\end{array}$ & $\begin{array}{r}2 \\
999\end{array}$ & $\begin{array}{l}435 \\
890\end{array}$ & $\begin{array}{r}1,000 \\
861\end{array}$ \\
\hline Chasing & $\begin{array}{r}1,000 \\
962\end{array}$ & $\begin{array}{r}1,000 \\
233\end{array}$ & $\begin{array}{r}1,000 \\
172\end{array}$ & $\begin{array}{r}8 \\
999\end{array}$ & $\begin{array}{l}1,000 \\
1,000\end{array}$ & $\begin{array}{l}435 \\
885\end{array}$ & $\begin{array}{r}1,000 \\
968\end{array}$ & $\begin{array}{r}1,000 \\
861\end{array}$ & $\begin{array}{r}1,000 \\
909\end{array}$ & $\begin{array}{r}1,000 \\
976\end{array}$ \\
\hline Fleeing & $\begin{array}{r}1,000 \\
936\end{array}$ & $\begin{array}{r}1,000 \\
95\end{array}$ & $\begin{array}{l}133 \\
947\end{array}$ & $\begin{array}{l}716 \\
645\end{array}$ & $\begin{array}{l}135 \\
989\end{array}$ & $\begin{array}{l}1,000 \\
1,000\end{array}$ & $\begin{array}{r}1,000 \\
952\end{array}$ & $\begin{array}{r}1,000 \\
811\end{array}$ & $\begin{array}{r}1,000 \\
868\end{array}$ & $\begin{array}{r}1,000 \\
963\end{array}$ \\
\hline Submission & $\begin{array}{r}1,000 \\
959\end{array}$ & $\begin{array}{r}75 \\
979\end{array}$ & $\begin{array}{r}1,000 \\
188\end{array}$ & $\begin{array}{r}1,000 \\
434\end{array}$ & $\begin{array}{r}1,000 \\
913\end{array}$ & $\begin{array}{r}1,000 \\
598\end{array}$ & $\begin{array}{l}1,000 \\
1,000\end{array}$ & $\begin{array}{r}1,000 \\
877\end{array}$ & $\begin{array}{r}85 \\
997\end{array}$ & $\begin{array}{r}1,000 \\
978\end{array}$ \\
\hline Bite/Butt & $\begin{array}{r}1,000 \\
955\end{array}$ & $\begin{array}{l}190 \\
933\end{array}$ & $\begin{array}{l}530 \\
741\end{array}$ & $\begin{array}{r}1,000 \\
443\end{array}$ & $\begin{array}{r}1,000 \\
906\end{array}$ & $\begin{array}{r}1,000 \\
573\end{array}$ & $\begin{array}{r}1,000 \\
973\end{array}$ & $\begin{array}{l}1,000 \\
1,000\end{array}$ & $\begin{array}{r}1,000 \\
917\end{array}$ & $\begin{array}{r}1,000 \\
976\end{array}$ \\
\hline Tail beat & $\begin{array}{r}1,000 \\
906\end{array}$ & $\begin{array}{r}1 \\
1,000\end{array}$ & $\begin{array}{r}1,000 \\
23\end{array}$ & $\begin{array}{r}1,000 \\
172\end{array}$ & $\begin{array}{r}1,000 \\
829\end{array}$ & $\begin{array}{r}1,000 \\
299\end{array}$ & $\begin{array}{r}1,000 \\
930\end{array}$ & $\begin{array}{r}1,000 \\
731\end{array}$ & $\begin{array}{l}1,000 \\
1,000\end{array}$ & $\begin{array}{r}1,000 \\
949\end{array}$ \\
\hline Fight & $\begin{array}{r}1,000 \\
971\end{array}$ & $\begin{array}{r}65 \\
987\end{array}$ & $\begin{array}{r}1,000 \\
368\end{array}$ & $\begin{array}{r}1,000 \\
621\end{array}$ & $\begin{array}{r}1,000 \\
949\end{array}$ & $\begin{array}{r}1,000 \\
723\end{array}$ & $\begin{array}{r}1,000 \\
978\end{array}$ & $\begin{array}{r}1,000 \\
922\end{array}$ & $\begin{array}{r}1,000 \\
947\end{array}$ & $\begin{array}{l}1,000 \\
1,000\end{array}$ \\
\hline
\end{tabular}

Threatening, Charging, and Bite/Butt; group 2 contains Submission, Tail beating, Withdrawal, and Fleeing. In the first group, the four behavior elements apparently form a linear progression of aggressive intensity and a natural series of transitions. Significantly low counts help to confirm this idea. For instance, Approach is unlikely to be immediately followed by Charging or Bite/Butt. On the other hand, the analysis suggests that Threatening is more likely to be an aggressive act leading to Charging than it is to be the expression of a balanced motivational conflict. Typical threatening behavior is usually followed by both attack and escape. In contrast, what we had called Threatening in white sea-bream was significantly followed only by Charging and was significantly less frequently followed by Fleeing than would be predicted by independence. In addition, Charging was also unlikely to be followed by Withdrawal and Fleeing, which confirms the high level of aggressive motivation associated with Charging. At the same time, these strong associations from Approach to Charging and the unlikely transitions from these elements to others associated with defeat, like Fleeing, strongly suggest that an animal that initiates an agonistic interaction is likely to be the winner. This possibility is plausible if we remember that these fishes lived together for several weeks and probably had enough time to establish clear dominance orders. Our unpublished observations showed a strong correlation between the initiation of an encounter and the probability of winning it in the fishes studied. In the second group of behaviors, Submission was significantly followed by Tail beating and Withdrawal, which in turn led to Fleeing. Tail beating, which we had supposed to be a form of overt aggression, deserves a closer examination, since it was significantly followed by
Withdrawal and significantly preceded by Submission. Could it be a form of defensive aggression by an animal that is in the process of losing an encounter?

The exploration of the data presented in this paper was not exhaustive and its meaning in the context of the biology of the species studied was not even discussed. However, our aim was to present a statistical procedure and exemplify ways in which the combined analysis of the values significantly higher and significantly lower than predicted by independence may yield meaningful behavioral insights and conclusions. We also tried to demonstrate how, with the help of appropriate tools, even small samples like our newt data set, may uncover several interesting relationships.

Obviously, ACTUS2 is not a universal solution to the many statistical problems raised by transition analysis. For instance, the thorny issue of stationarity (Oden 1977), a condition often not met in transition analysis, is not solved simply by using this procedure. This problem arises because individuals are not static machines that perform different behavioral acts with fixed probabilities. For instance, during a social interaction, both physiological state and information available about the state of other participants change as the interaction proceeds, so samples collected in different phases of a long interaction are not comparable and the probabilities of occurrence of different acts and transitions are not stable along the sequence. Oden (1977) illustrated one of several possible solutions to the problem.

Another problem that is not solved by ACTUS2 results from the frequent need to remove data coming from several individuals. A few individual with a very atypical behavior may bias a sample, generating a pattern that is not representative of the more common situations. In 
addition, this type of procedure cannot capture the variability between individuals, being unable to detect biologically relevant alternatives that different animals may adopt when faced with a given situation. One way to minimize the limitations of removing data is to use information from a large number of individuals and to ensure that the sampling effort is distributed equally among them. These, however, will not solve the problem of losing inter-individual variability.

The procedure described in this paper has the advantage, as stated above, of requiring small amounts of data and being able to deal with very low frequencies. This means that, in the future, it can be applied to data from individual animals. This will make it possible to compare the salient features coming from many different individuals, opening the way to a subsequent exploration of variation and similarity among them.

Finally, transitions involving more than two consecutive acts are outside the scope of the solution implemented in this study (but see Hazlett and Estabrook 1974). However, ACTUS2 solves several of the traditional difficulties of transition analysis and exemplifies how simulation statistics may help us develop new tools to investigate questions about behavior.

Acknowledgements This work was partially suported by the Fundação para a Ciência e Tecnologia, through the Programa Plurianual de Apoio às Unidades de Investigação. We thank the reviewers for their close reading of our manuscript and for their constructive suggestions. All experiments complied with the current laws of Portugal.

\section{References}

Almada VC, Santos RS (1995) Parental care in the rocky intertidal: a case study of adaptation and exaptation in Mediterranean and Atlantic blennies. Rev Fish Biol Fisheries 5:23-37

Arntzen JW, Sparreboom M (1989) A phylogeny for the Old World newts, genus Triturus: biochemical and behavioral data. J Zool 219:645-664

Bakeman R, Gottman JM (1986). Observing interaction: an introduction to sequential analysis. Cambridge University Press, Cambridge

Chatfield C, Lemon RE (1970) Analysing sequences of behavioral events. J Theor Biol 29:427-445

Christiansen R (1997) Log-linear models and logistic regression. Springer, Berlin Heidelberg New York

Efron B (1979) Computers and the theory of statistics: thinking the unthinkable. Soc Ind Appl Math Rev 21:460-480

Efron B, Tibshirani R (1986) Boot strap methods for confidence intervals and other measures of statistical accuracy. Stat Sci $1: 54-77$
Estabrook CB, Estabrook GF (1989) ACTUS: a solution to the problem of analysing sparse contingency tables. Hist Meth 22:5-8

Fagen RM, Mankovich NJ (1980) Two-act transitions, partitioned contingency tables, and the "significant cells" problem. Anim Behav 28:1017-1023

Faria MM (1993) Sexual behavior of Bosca's newt, T. boscai. Amph-Rept 14:169-185

Faria MM (1995) A field study of reproductive interaction in Bosca's newt, T. boscai. Amph-Rept 16:357-374

Feinberg SE (1987) The analysis of cross-classified categorical data. MIT Press, Cambridge

Gama P (1989) Discussão de alguns métodos de análise de sequências comportamentais. Anál Psicol 1-3(VII):121-132

Gonçalves EJ, Almada VC (1997) Sex differences in resource utilization by the peacock blenny (Salaria pavo). J Fish Biol 51:624-633

Gonçalves EJ, Almada VC (1998) A comparative study of territoriality in intertidal and subtidal blennioids (Teleostei: Blennioidei). Environ Biol Fishes 51:257-264

Green AJ (1989) The sexual behavior of the great crested newt, $T$. cristatus (Amphibia: Salamandridae). Ethology 83:129-153

Griffiths RA (1996) Newts and salamanders of Europe. Poyser, London

Halliday TR (1974) Sexual behavior of the smooth newt, Triturus vulgaris (Urodela, Salamandridae). J Herpetol 8:277-292

Hazlett BA, Estabrook G (1974) Examination of agonistic behavior by character analysis. II. Hermit crabs. Anim Behav 19:1-17

Manly BFJ (1997) Randomization, bootstrap and Monte Carlo methods in biology. Chapman and Hall, London

Marriott FHC (1979) Barnard's Monte Carlo tests: how many simulations? Appl Stat 28:75-77

Martin P, Bateson P (1993) Measuring behaviour. An introductory guide, 2nd edn. Cambridge University Press, Cambridge

Oden N (1977) Partitioning dependence in nonstationary behavioral sequences. In: Hazlett B (ed) Quantitative methods in the study of animal behavior. Academic Press, New York, pp 203-220

Oliveira RF, Almada VC (1998) Dynamics of social interactions during group formation in males of the cichlid fish Oreochromis mossambicus (Teleostei: Cichlidae). Acta Ethol 1:57-70

Robalo JI, Almada VC (in press)

Slater PJB (1973) Describing sequences of behavior. In: Bateson P, Klopfer P (eds) Perpectives in ethology. Plenum, New York, pp 131-153

Slater PJB, Ollason JC (1972) The temporal pattern of behaviour in isolated male zebra finches: transition analysis. Behaviour 42:248-269

Sparreboom M, Teunis B (1990) The courtship display of the marbled newt Triturus marmoratus. Amph-Rept 11:351-361

Steinberg JB (1977) Information theory as an ethological tool. In Hazlett B (ed) Quantitative methods in the study of animal behavior. Academic Press, New York, pp 47-74

Thomas L (2000) A course in categorical data analysis. Chapman and Hall, London

Zuiderwijk A (1986) Interaction et accouplement du triton creté et du triton marbré (Urodela, Salamandridae). Méthodes d'observation. Bull Soc Herpetol Fr 40:28-35

Zuiderwijk A (1990) Sexual strategies in the newts T. cristatus and T. marmoratus. Bjdr Dierkd 60:51-64 